\title{
Editorial: Conservation and Management of Large Carnivores-Local Insights for Global Challenges
}

\author{
Tasos Hovardas ${ }^{1,2 *}$, Vincenzo Penteriani ${ }^{3}$, Arie Trouwborst ${ }^{4}$ and José Vicente López-Bao ${ }^{3}$ \\ ${ }^{1}$ Research in Science and Technology Education Group, University of Cyprus, Nicosia, Cyprus, ${ }^{2}$ CALLISTO-Wildlife and \\ Nature Conservation Society, Thessaloniki, Greece, ${ }^{3}$ Research Unit of Biodiversity, (UMIB, CSIC-UO-PA), Campus Mieres, \\ Mieres, Spain, ${ }^{4}$ Tilburg Law School, Tilburg University, Tilburg, Netherlands
}

Keywords: large carnivores, population trends, damage, attitudes, policy, multi-stakeholder governance, legal frameworks, legal procedures

Editorial on the Research Topic

Conservation and Management of Large Carnivores-Local Insights for Global Challenges

Large carnivores present multiple conservation challenges for various stakeholders across geographical scales and socio-cultural contexts. There have been many manifestations of humancarnivore conflict worldwide but also positive examples of human-carnivore coexistence. To contribute to the ongoing debate on large carnivore conservation and management, we present this Research Topic with a collection of 19 articles, which address a variety of species in a range of geographical and socio-cultural contexts. The articles focus on four themes: (1) population trends and damage caused by large carnivores; (2) attitudes, communication and policy; (3) multi-stakeholder governance; and (4) legal frameworks and procedures. Our overall objective is to provide a set of evidence-based approaches for human-carnivore coexistence as well as discuss contested areas, disagreements, and tensions, provide fresh insight, and inform policy and stakeholder interaction. Since there can be many different models of engagement and dispute as to their outcomes, this Research Topic will explore different perspectives to help develop alternative strategies aimed at delivering solutions.

\section{POPULATION TRENDS AND DAMAGE CAUSED BY LARGE CARNIVORES}

This article was submitted to Conservation and Restoration

a section of the journal

Frontiers in Ecology and Evolution

Four papers in the Research Topic deal with population dynamics of and damage caused by large carnivores. Ugarte et al. present a global review of scientific literature on carnivore-livestock conflicts, which covered three decades (1992-2019). A substantial majority of the papers selected referred to Asian and African countries and focused on Felidae and Canidae. Carnivores mostly preying on domestic animals displayed increased home range and body mass and manifested a generalist habitat behavior. Livestock depredation increased with vegetation cover and decreased with distance from human settlements. The authors note that available evidence did not support an effect of wild prey density on livestock depredation.

Hoffmann et al. used data collected in the Maasai steppe of Tanzania (2009-2013) to examine spatial autocorrelation within livestock depredation at the household scale (bomas). Spatial patterns in livestock depredation by large carnivores (lions, leopards, spotted hyenas, black-backed jackals, cheetahs) did not differ from random. The authors note that this result may either reflect the interplay of other processes which obscure spatial patterns of livestock depredation or that consumption of livestock prey in the study area, indeed, does not display any spatial pattern, with both alternatives necessitating further research. 
Dalerum et al. investigated if temporal variation in large carnivore densities (brown bear, gray wolf, Eurasian lynx) are followed by analogous variation in depredation (cattle, sheep, domestic dogs). Working with a data set of 20 years from Sweden, the authors show that wolf densities were more frequently associated with number of damages as compared to brown bear and lynx. The authors highlight that damages caused by large carnivores are highly context-dependent and the relation of large carnivore population size to damages is not always proportional, implying the regulative role of other factors.

Treves et al. present a design for a platinum-standard experiment for predator control to protect domestic animals. The authors suggest that this design can advance existing approaches in five pending questions: (1) If survivors prey on domestic animals after removals at similar rates; (2) if surviving predators compensate for vacancies by altered reproduction rates; (3) how much predation on domestic prey is compensatory; (4) how do sympatric species of predators respond to removal of competitors; and (5) if one source of predator removal affects other sources.

\section{ATTITUDES, COMMUNICATION, AND POLICY}

Articles focusing on attitudes toward large carnivores, communication and policy delve deeper in underexplored interrelations between various variables. Nanni et al. analyzed the effect of graphic/sensationalist (discursive) content, presence of images, and newspaper coverage (local, national or worldwide) in driving the number of total shares of online newspaper reports on predator attacks on humans. The authors underline that information propagated in social media is biased toward a graphic/sensationalistic depiction of predators, which could result in spreading unjustified fear and prejudice against these species, lower tolerance levels and decreased support for their conservation.

In a Swedish context, Johansson et al. evaluated communication interventions aimed to address participant fear of brown bears. Information meetings were found to reduce participants' self-reported fear, which lasted for at least one semester. Information meetings were also efficient in reducing perceived vulnerability in a potential brown bear encounter (e.g., by predicting the animal's behavior or controlling one's own reaction in the event of an encounter) and in increasing positive affective experience in response to brown bears.

Knox et al. investigated indigenous norms, attitudes and behavior toward jaguars in the Bolivian Amazon. They found that descriptive norms (reports that participant's neighbors killed jaguars) and subjective norms (reports that a family member/neighbor thought jaguar killing was good) influenced positively attitudes toward killing and self-reported past killing of jaguars. In addition, reported attacks of jaguars on humans were associated with attitudes toward killing and self-reported past killing of jaguars. The authors note that these effects combined with illegal trade of jaguar parts are likely to enhance jaguar persecution in the Bolivian Amazon.
Lute and Carter compared between three different contexts in the USA (Mexican gray wolves in Arizona and New Mexico; grizzly bears in the Greater Yellowstone Ecosystem; coyotes throughout the American West) in terms of land sharing, coadaptation and risk tolerance. Although coyotes do not have a protected status, land sharing was found to be supported for this species and co-adaptation with coyotes was evident. In contrast to grizzly bears, for which risk tolerance was deemed achievable, the wolf case was distinguished by challenges related to risk tolerance and substantial differences between stakeholder views, in this regard.

Implementing an integrated design to study the effect of values, identity and place on wolf attitudes, Carlson et al. found no association of sociodemographics with attitudes and that attitudes did not differ between rural regions with or without wolves. In rural areas with wolf presence, identification with interest groups was associated with wolf attitudes (negatively for "farmer"/"rancher"; positively for "environmentalist"/“animal rights advocate"). The addition of wildlife value orientations dampened the effect of place (mutualism positively correlated with wolf attitudes; domination negatively correlated with wolf attitudes).

Hughes et al. outlined the major problem perspectives related to the grizzly bear recovery policy in Alberta, Canada. Participants from government, landowners (farmers and ranchers), the natural resource sector (forestry, petroleum industry, mining), and environmental NGOs highlighted lack of policy clarity, inefficiencies in implementation and challenges in policy decision-making and governance. In line with what will be described in the next section of this editorial in relation to multi-stakeholder governance, participants desired a shift from the current technocratic and elitist approach toward a decentralized and inclusionary process.

\section{MULTI-STAKEHOLDER GOVERNANCE}

Several articles reported on multi-stakeholder governance schemes focusing on large carnivores in North America and Europe. Bogezi et al. examined how stakeholders perceived certification of predator(wolf)-friendly beef in a North American context (Washington State, USA). Responses were trichotomized between stakeholders who endorsed the scheme (e.g., wildlife agency personnel; environmental NGO employees), those who showed least support (e.g., hunters; country politicians) and most rangers, for whom support was moderate. Rather than seeing it as just an economic incentive, ranchers valued the scheme as an outreach opportunity to foster the social acceptability of ranching.

Morehouse et al. documented how a community-based program aimed to mitigate human-carnivore conflict in a protected area in Canada succeeded in reducing perceived conflict, perceived safety risk from large carnivores and confidence in using mitigation tools. A parallel analysis that was run with complaint data related to large carnivore conflicts (1999-2016) indicated that the trend of attractant and 
deadstock-based incidents turned from increasing to decreasing after the introduction of the program in 2009.

In their analysis of stakeholder networks in 14 European countries, Grossmann et al. showcased how hunters, livestock owners and environmentalists/nature conservationists, and with a lesser frequency, governmental departments, foresters and scientists, interacted when dealing with large carnivore issues. The authors revealed how ingroup homogeneity was generalized by stakeholders at the expense of ingroup heterogeneity, while intergroup homogeneity was downplayed. Overall, stakeholders were found to acknowledge the effort to better understand rival perspectives.

In an examination of two regional multi-stakeholder governance schemes, one in Norway and another one in Sweden, Sjölander-Lindqvist et al. noted a tension between the national and regional scale. Although regional schemes were meant to decentralize large carnivore governance, in both cases they were found to be overruled by national agencies in the final decisions taken. This lack of power was accompanied by favoritism of scientific knowledge and dismissal of local knowledge.

Salvatori et al. mapped stakeholder positions across four regional platforms established in Europe for promoting coexistence between people and large carnivores (Ávila, Spain; Grosseto, Italy; Trento, Italy; Harghita, Romania). The authors identified lack of trust and genuine communication between stakeholders, especially, local actors and regional authorities, as a major driver of immanent conflict related to large carnivores. A crucial shortcoming in all contexts was inability to access or share credible information on large carnivore data.

Hovardas presents a Greek case study with the implementation of a methodology for stakeholder engagement, which is based on three subsequent stages (stakeholder analysis; stakeholder consultation and involvement; participatory scenario development). Stakeholder interaction is scaffolded by means of social learning templates (Strengths, Weaknesses, Opportunities, and Threats analysis template; mixed-motive template; template for participatory scenario development). This toolkit can be employed to structure stakeholder input and interaction and empower local stakeholders to take ownership of multi-stakeholder governance.

\section{LEGAL FRAMEWORKS AND PROCEDURES}

Three articles of the Research Topic concentrate on legal frameworks and procedures related to large carnivores. Epstein and Kantinkoski report on a Finnish nature protection organization, which appealed wolf hunting permits granted by the Finnish Wildlife Agency to prevent poaching by arguing that non-lethal alternatives to hunting were not properly considered. Based on a preliminary ruling requested by the Finnish Supreme Administrative Court from the Court of Justice of the EU, the former ruled that, indeed, hunting permits violated the Finnish hunting law.

Lewis and Trouwborst concentrate on the Convention on the Conservation of Migratory Species of Wild Animals (CMS) and discuss its relevance for large carnivores. Specifically, they underline that CMS has the potential to contribute to transboundary conservation of large carnivores, provided that due attention is paid to avoiding duplication of efforts so that resources are invested wisely and real added value is secured. The authors note that additional interpretative guidance is necessary regarding the application of the Convention to lethal management and sustainable use of large carnivores.

Hellinx focuses on the Joint CMS-CITES African Carnivores Initiative (ACI), which presents a synergy between the aforementioned CMS and the Convention on International Trade in Endangered Species of Wild Fauna and Flora (CITES). The author problematizes the effectiveness of the ACI in coordinating international conservation efforts for large carnivores and cautions that sufficient financial resources for materializing this initiative is not yet secured.

\section{INTERDISCIPLINARITY AND INCLUSION}

A main conclusion to be drawn from the overview of this Research Topic is that research questions and recommendations for future research were all characterized by an increased interest in interdisciplinarity, showcasing the necessity of crossfertilizing natural and social data. Moreover, novel approaches in studying stakeholder attitudes, communication and policy were accompanied by the examination of recent initiatives in multi-stakeholder governance in large carnivore conservation and management. We anticipate that such inclusionary schemes will attract more attention from scholars worldwide in the years to come. Furthermore, the analyses of legal frameworks and procedures included in this Research Topic enrich the debate on policy implications at various scales. We are grateful to all authors who published their work in the Research Topic for unraveling these interdisciplinary and inclusionary approaches and we are thankful to Frontiers editors and reviewers who helped us conclude editorial operations. We believe that the Research Topic will make an important contribution to the field by offering local insights for global challenges in large carnivore conservation and management.

\section{AUTHOR CONTRIBUTIONS}

TH prepared the draft manuscript. VP, AT, and JL-B reviewed the draft. All authors contributed to the article and approved the submitted version.

Conflict of Interest: The authors declare that the research was conducted in the absence of any commercial or financial relationships that could be construed as a potential conflict of interest.

Copyright (c) 2021 Hovardas, Penteriani, Trouwborst and López-Bao. This is an open-access article distributed under the terms of the Creative Commons Attribution License (CC BY). The use, distribution or reproduction in other forums is permitted, provided the original author(s) and the copyright owner(s) are credited and that the original publication in this journal is cited, in accordance with accepted academic practice. No use, distribution or reproduction is permitted which does not comply with these terms. 